\title{
Synthesis, Characterization and Anti-diabetic activity of 1,3,5-triaryl-2-pyrazolines in acetic acid solution under Ultrasound Irradiation
}

\author{
M. Emayavaramban ${ }^{2}$, N. Santhi ${ }^{1, \star}$, C. Gopi ${ }^{2}$, C. Manivannan ${ }^{2}$, A. Raguraman ${ }^{2}$ \\ ${ }^{1}$ Department of Chemistry, Government Arts College, C. Mutlur, \\ Chidambaram, Tamil Nadu, India \\ ${ }^{2}$ Department of Chemistry, Manonmaniam Sundaranar University, Tirunelvel - 627012, \\ Tamil Nadu, India \\ *E-mail address: nsaanthi@gmail.com
}

\begin{abstract}
A chalcone was prepared by the reaction of 4-methylbenzaldehyde with 4-methylacetophenone in dilute methanolic sodium hydroxide solution under ultrasonic irradiationin the water bath of an ultrasonic cleaner at room temperature. Treatment of this chalcone with thiosemicarbazide / semicarbazide hydrochloride / benzhydrazide / benzenesulphonyl hydrazide / phenylhydrazine hydrochloride afforded the corresponding 2-pyrazoline in good yields. All the new compounds have been characterized by IR, ${ }^{1} \mathrm{H}-\mathrm{NMR},{ }^{13} \mathrm{CNMR}$ spectral data. All the target compounds were evaluated for their in-vivo anti - diabetic activity in rates in comparison with as reference drug.
\end{abstract}

Keywords: Chalcone; Pyrazoline; ultrasound irradiation; Anti-diabtic activity and Alloxan Monohydrate

\section{INTRODUCTION}

Diabetes mellitus is a common and very prevalent disease affecting the citizens of both developed and developing countries. It is estimated that $25 \%$ of the world population is affected by this disease. Diabetes mellitus is caused by the abnormality of carbohydrate metabolism which is linked to low blood insulin level or insensitivity of target organs to insulin [1]. Diabetes mellitus is a chronic disease that occurs either when the pancreas does not produce enough insulin or when the body cannot effectively use the insulin it produces. Insulin is a hormone that regulates blood sugar. Defective insulin secretion is the major cause for chronic hyperglycemia resulting in impaired function or serious damage to many of the body's systems, like eyes, kidneys, nerves, heart and blood vessels [2,3]. The common signs and symptoms are excessive thirst and urination, weight loss or gain, fatigue, and influenzalike symptoms. Early diabetes symptoms can be very mild and often even unnoticeable. Diabetes mellitus is one of the common metabolic disorders with micro and macro vascular complications that results in significant morbidity and mortality. It is considered as one of the five leading causes of death in the world [4,5]. Diabetes mellitus is a group of syndromes 
characterized by hyperglycemia, altered metabolism of lipids, carbohydrates and proteins and an increased risk of complications from vascular diseases. Most patients can be classified clinically as having either Type 1 diabetes mellitus. Historically, different substituted pyrazoles [6] were known for their hypoglycemic activity in vivo, but in a search for novel structural classes of drugs inhibiting the activity of the ATP- $\mathrm{K}^{+}$channel of the beta cell pancreatic membrane, inducing the production of insulin we turned our attention to substituted pyrazoline derivatives. The pyrazole ring is a prominent structural motif found in numerous pharmaceutically active compounds. 2-Pyrazolines display a broad spectrum of potential pharmacological activities and are present in a number of pharmacologically active molecules such as phenazone/ amidopyrene/ methampyrone (analgesic and antipyretic), azolid/ tandearil (anti-inflammatory), indoxacarb (insecticide) and anturane (uricosuric). Changes in their structure have offered a high degree of diversity that has proven useful for the development of new therapeutic agents having improved potency and lesser toxicity.

The title compound Pyrazoline is five-membered heterocyclic having two adjacent nitrogen atoms within the ring. It has only one endocyclic double bond and is basic in nature [7]. It plays a crucial role in the development of theory in heterocyclic chemistry and is also extensively used as useful synthons in organic synthesis [8]. Pyrazolines have been reported to show a broad spectrum of biological activities including antibacterial [9] antifungal [10], anti-inflammatory [11], analgesic [12], antipyretic [13], insecticidal [14], diuretic [15], cardiovascular [16] and antidepressant activities [17]. It was thought of interest to synthesize some new pyrazoline derivatives starting from chalcone and various hydrazides.

\section{MATERIALS AND METHODS}

All chemicals were obtained from commercial sources and used without any further purification. All the melting points were determined by digital melting point apparatus. IR spectra were recorded in Shimadzu FT-IR-8400 instrument using KBr pellet method.

The ${ }^{1} \mathrm{H}$ NMR spectral data were recorded on Bruker AV $400 \mathrm{MHz}$ in DMSO and $\mathrm{CDCl}_{3}$ using TMS as an internal standard. The purity of the synthesized compounds was ascertained by TLC using iodine vapour as visualizing agents.

\section{EXPERIMENTAL METHODS}

\section{1. Preparation of (E)-1,3-dip-tolylprop-2-en-1-one (1)}

4-methylbenzaldehyde (2.5 mmole), 4-methylacetophenone $(2.5 \mathrm{mmol}), 95 \%$ Ethanol $(20 \mathrm{~mL})$ and $2 \mathrm{~N} \mathrm{NaOH}(3 \mathrm{~mL})$ were taken into a $100 \mathrm{~mL}$ conical flask. The mixture was irradiated by an ultrasonic generator in a water-bath at $30-35{ }^{\circ} \mathrm{C}$ for $3 \mathrm{~min}$. The product was filtered with suction on a Buchner funnel, washed with cold water until the washings were neutral to litmus and then with ice cold ethanol. The crude product was recrystallized from ethanolto afford greenish yellow shiny crystals.

\section{2. Preparation of 4,5-dihydro-3,5-dip-tolylpyrazole-1-carboxamide (2)}

(E)-1,3-dip-tolylprop-2-en-1-one, (2.5 mmole), semicarbazide hydrochloride, (2.5 mmole) and gl. acetic acid $(20 \mathrm{~mL})$ were taken intoa $100 \mathrm{~mL}$ conical flask. This reaction flask was suspended at the center of the ultrasonic cleaning-bath to get the maximum ultrasound energy and sonicated until crystals appeared or starting chalcone disappeared. The reaction- 
mixture was poured into crushed ice and left overnight. The precipitate was separated by filtration, washed well with water, dried and recrystallized from ethanol to afford yellow coloured crystals

\section{3. Preparation of 4,5-dihydro-3,5-dip-tolylpyrazole-1-carbothioamide (3)}

(E)-1,3-dip-tolylprop-2-en-1-one, (2.5 mmole), thiosemicarbazide, (2.5 mmole) and gl. acetic acid $(20 \mathrm{~mL})$ were taken into a $100 \mathrm{~mL}$ conical flask. This reaction flask was suspended at the center of the ultrasonic cleaning-bath to get the maximum ultrasound energy and sonicated until crystals appeared or starting chalcone disappeared. The reaction-mixture was poured into crushed ice and left overnight. The precipitate was separated by filtration, washed well with water, dried and recrystallized from ethanol to afford yellow coloured crystals.

\section{4. Preparation of 4,5-dihydro-1-phenyl-3,5-dip-tolyl-1H-pyrazole (4)}

(E)-1,3-dip-tolylprop-2-en-1-one, (2.5 mmole), phenylhydrazine hydrochloride (2.5 mmole) and gl. acetic acid $(20 \mathrm{~mL})$ were taken into $100 \mathrm{~mL}$ conical flask. This reaction flask was suspended at the center of the ultrasonic cleaning-bath to get the maximum ultrasound energy and sonicated until crystals appeared or starting chalcone disappeared. The reactionmixture was poured into crushed ice and left overnight. The precipitate was separated by filtration, washed well with water, dried and recrystallized from ethanol to afford yellow coloured crystals.

\section{5. Preparation of (4,5-dihydro-3,5-dip-tolylpyrazol-1-yl)(phenyl)methanone (5)}

(E)-1,3-dip-tolylprop-2-en-1-one(2.5 mmole), benzhydrazide(2.5 mmole) and gl. acetic acid $(20 \mathrm{~mL})$ were taken into a $100 \mathrm{~mL}$ conical flask. This reaction flask was suspended at the center of the ultrasonic cleaning-bath to get the maximum ultrasound energy and sonicated until crystals appeared or starting chalcone disappeared. The reaction-mixture was poured into crushed ice and left overnight. The precipitate was separated by filtration, washed well with water, dried and recrystallized from ethanol to afford yellow coloured crystals.

\section{6. Preparation of 3,5-bis(4-methylphenyl)-1-(phenylsulfonyl)-4,5-dihydro-1H-pyrazole} (6)

(E)-1,3-dip-tolylprop-2-en-1-one,(2.5mmole), benzene sulphonylhydrazide(2.5 mmole) and gl. acetic acid $(20 \mathrm{~mL})$ were taken intoa $100 \mathrm{~mL}$ conical flask. This reaction flask was suspended at the center of the ultrasonic cleaning-bath to get the maximum ultrasound energy and sonicated until crystals appeared or starting chalcone disappeared. The reaction-mixture was poured into crushed ice and left overnight. The precipitate was separated by filtration, washed well with water, dried and recrystallized from ethanol to afford yellow coloured crystals.

\section{ANTIDIABETIC ACTIVITY}

\section{1. Experimental Animals}

Wistar albino adult male rats weighing 150-200 g were obtained from the animal house Bharathidasan University, Tiruchirappalli, India. The animal were grouped and housed in polyacrylic cages $(38 \times 23 \times 10 \mathrm{~cm})$ with not more than six animals per cage and maintained under standard laboratory under standard laboratory conditions (temperature $25+2{ }^{\circ} \mathrm{C}$ ) with 
dark and light cycle (14/10 hour). They were allowed free access to standard dry pellet diet (Hindustan Lever, Kolkata, India) and water ad libitum. The mice were acclimatized to laboratory condition for 10 days before commencement of experiment. The experimental protocol was approved by Institutional Animal Ethical Committee (IAEC) constitutedunder CPCSEA.

\section{2. Experimental design}

The animals were randomly divided into 9 groups containing six rats in each group:

$\begin{array}{lll}\text { Group I } & - & \text { Served as normal control } \\ \text { Group II } & - & \text { Animals were served with Alloxan monohydrate } \\ \text { Group III } & - & \text { Induced Animals were treated with Insulin } \\ \text { Group IV } & - & \text { Induced Animals were treated with drug 1 } \\ \text { Group V } & - & \text { Induced Animals were treated with drug 2 } \\ \text { Group VI } & - & \text { Induced Animals were treated with drug 3 } \\ \text { Group VII } & - & \text { Induced Animals were treated with drug 4 } \\ \text { Group VIII } & - & \text { Induced Animals were treated with drug 5 } \\ \text { Group IX } & - & \text { Induced Animals were treated with drug } 6\end{array}$

\section{3. Procedure}

Alloxan monohydrate $150 \mathrm{mg} / \mathrm{kg}$ body weights were dissolved in normal saline and injected intra peritoneal after $18 \mathrm{hrs}$ fasting to induce hyperglycemic group [18]. After one hour of alloxan administration the animals were fed on standard pellets and water ad libitum. The experimental animals were fasted for $18 \mathrm{hr}$. before alloxan injection. The blood glucose level was monitored after alloxanization in blood sample collected by tail tipping method using a glucometer. After $72 \mathrm{hr}$. the rats having blood glucose level above $250 \mathrm{mg} / \mathrm{dl}$ of blood were selected for the study and the animals were divided into 15 groups and each group contained six rats (WHO, 1980). Glucose level was measured using GlucoChek (Blood Glucose monitoring system). The procedure is as follows.

\section{4. Estimation of glucose}

The blood sample was collected in the tail portion of the albino rats. Wash the rat tail with warm, soapy water. Rinse well and dry them thoroughly. Tail was also clean with an alcohol pad to dry before testing. Prepare the lancing device. Take one test strip out of the test strip vial replace the vial cap immediately and close it tightly. Insert this test strip (with the black bars facing up) into the test strip of the meter .The meter turns on automatically, and the code number appears the test strip vial or can press the strip symbol which will instruct after to insert a test strip. Insert test strip with in 1 minute, then the meter will display the code number. Place the lancing device in rat's tail and press the trigger, gently squeeze the rat tail until get a drop of blood. The blood sample will be drawn into the test strip automatically, hear a beep letting know the test has begun. The blood glucose level display on the monitor.

\section{5. Statistical analysis}

Results are expressed as Mean \pm S.E.M. The difference between experimental groups was compared by One-way Analysis of Variance (ANOVA) followed by Dunnett's test. 


\section{RESULTS AND DISCUSSION}

In the present work, (E)-1,3-dip-tolylprop-2-en-1-one (1) was prepared by reaction of 4methylacetophenone with 4-methylbenzaldehyde in dilute methanolic sodium hydroxide solution under ultrasonic irradiationin the water bath of an ultrasonic cleaner at room temperature in accordance with the method described in the literature [19].

The chalcone 1 was then reacted with semicarbazidehydrochloride,thiosemicarbazide, phenylhydrazine hydrochloride, benzhydrazide and benzene sulphonylhydrazide to give 4,5dihydro-3,5-dip-tolylpyrazole-1-carboxamide(2),4,5-dihydro-3,5-dip-tolylpyrazole-1-

carbothioamide (3),4,5-dihydro-1-phenyl-3,5-dip-tolyl-1H-pyrazole(4), (4,5-dihydro-3,5-diptolylpyrazol-1-yl)(phenyl)methanone(5),3,5-bis(4-methylphenyl)-1-(phenylsulfonyl)-4,5dihydro-1H-pyrazole(6).

Table 1. The physical data of synthesized pyrazoline derivatives (1-6).

Structure




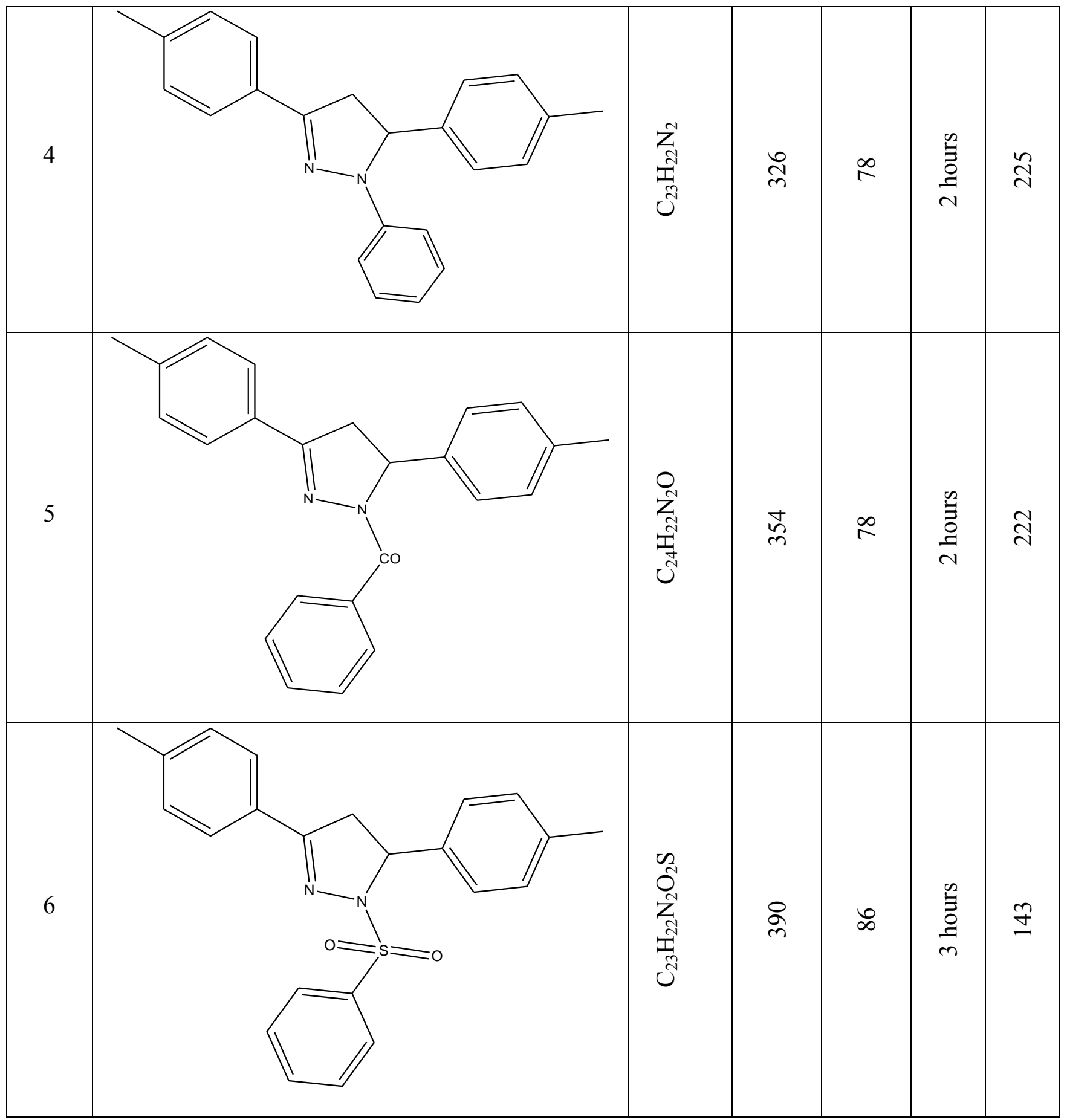

This reaction probably takes place through mediation of an appropriate $\alpha, \beta$-unsaturated hydrazone, which immediately cyclizes to give a 2-pyrazoline ring in the presence of a suitable cyclizing agent. The synthetic route of compounds 1-6 is outlined in Scheme 1. 


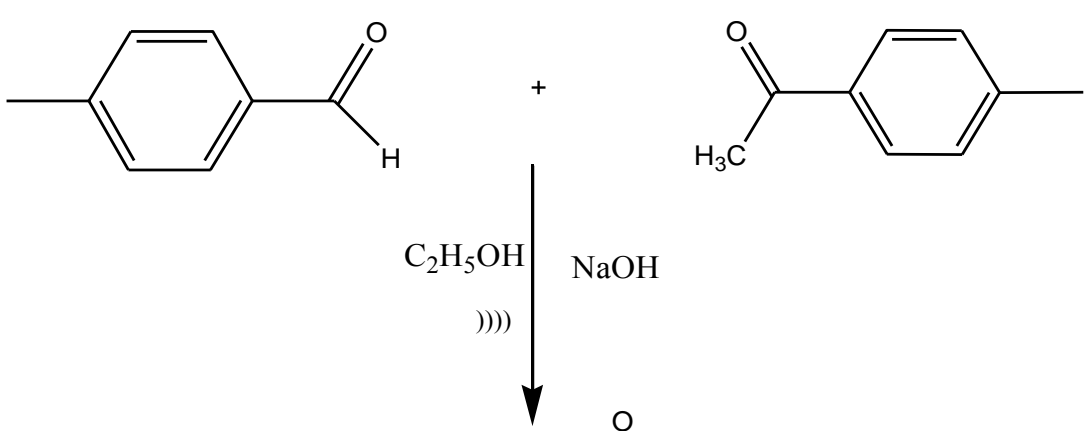<smiles>Cc1ccc(/C=C/C(=O)c2ccc(C)cc2)cc1</smiles>

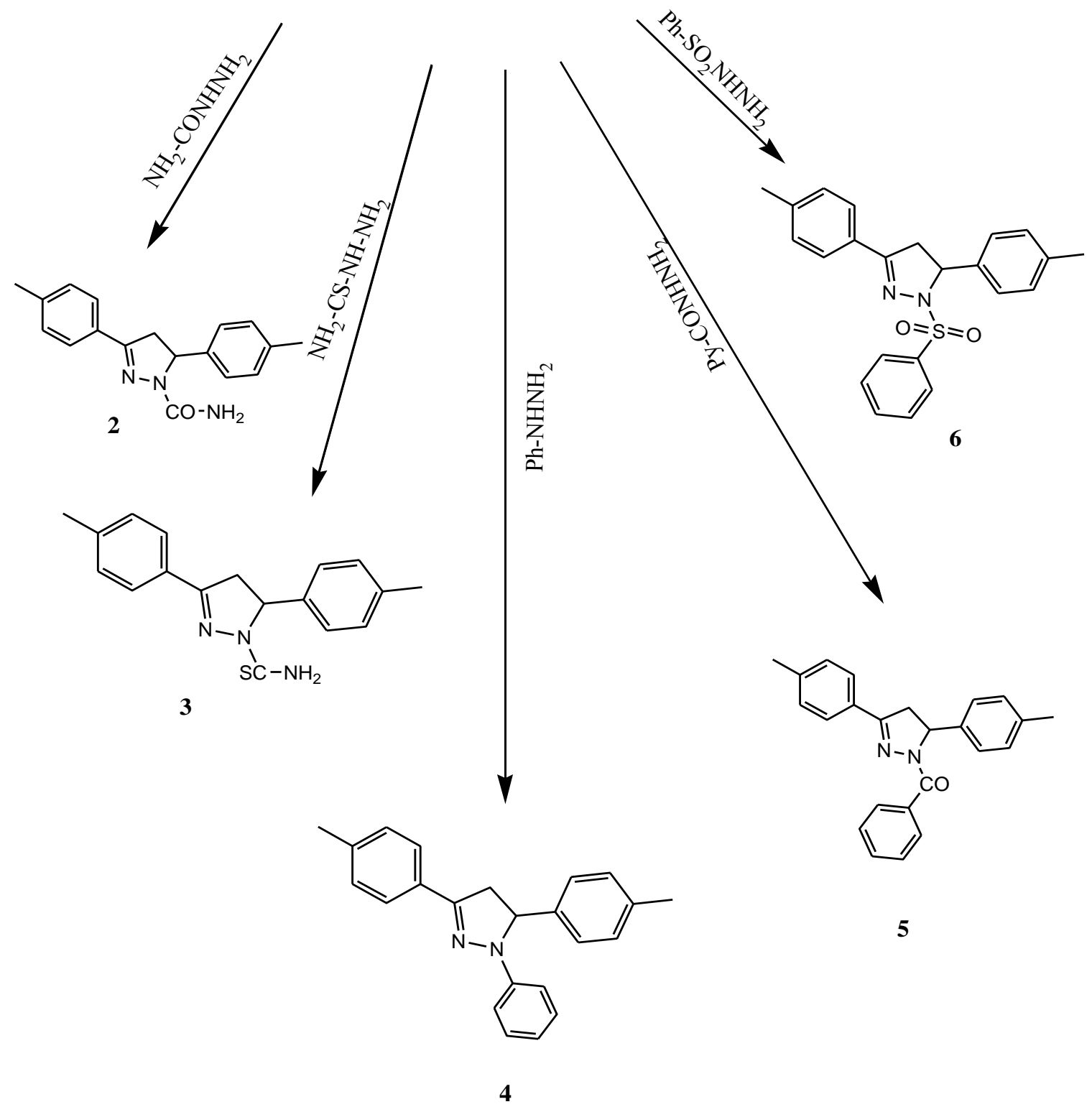

Scheme 1. Synthesis of pyrazoline derivatives (1-6). 
The physical data along with reaction time and yield of chalcone and pyrazoline derivatives was reported in Table 1. Ultrasound irradiation has been increasingly used inorganic synthesis in last three decades. Large number of organic reactions can be carried out in higher yield, shorter reaction time and milder conditions under ultrasonic irradiation ${ }^{[20]}$. It was observed that the reaction time decreased considerably and the yields of the products promoted in the presence of ultrasonic irradiation. Thus, ultrasound was found to have beneficial effect on the synthesis of chalcone and pyrazoline derivatives in which decrease time of above reactions from 8 to $10 \mathrm{~h}$ in conventional procedure to less than $1 \mathrm{~h}$, also, a noticeable improvement in yields of reactions under ultrasonic irradiations

Formation of the synthesized derivatives 1-6 were confirmed on the basis of their IR and ${ }^{1} \mathrm{H}-\mathrm{NMR}$ and ${ }^{13} \mathrm{C}$ NMR data. The IR spectral data of compound 1-6 are given in Table 2 . Selected diagnostic bands of the IR spectra of the chalcone showed useful information about the structure of the compounds. The IR spectra for synthesized chalcone observed the shifting of absorption band of carbonyl group for the two reactants 4-methyl acetophenone and 4methyl benzaldehyde is $1670 \mathrm{~cm}^{-1}$ to lower wave number $1650 \mathrm{~cm}^{-1}$, which is a strong evidence for the formation of conjugated enone of chalcone [21]. Other strong bands appeared at $1597 \mathrm{~cm}^{-1}$, corresponding to $\mathrm{C}=\mathrm{C}$ of the enone and aromatic rings, also the disappearance of aldehydic $(\mathrm{CH})$ bands is a good evidence for the formation of chalcones. The IR spectra of condensed product 2-6 displayed disappearance of the characteristic absorption at $1650 \mathrm{~cm}^{-1}$ for $-\mathrm{C}=\mathrm{O}$ of conjugated carbonyl and presence of characteristic absorption band at 1568-1597 due to $\mathrm{C}=\mathrm{N}$ of pyrazoline in the IR spectrum. Synthesized compounds 2-6 showed weak $\mathrm{C}-\mathrm{H}$ stretching bands near $3024-3098 \mathrm{~cm}^{-1}, \mathrm{C}=\mathrm{C}$ skeletal vibrations near $1469-1510 \mathrm{~cm}^{-1}$ for aromatic and absorption around $2918-2923 \mathrm{~cm}^{-1}$ for aliphatic nature of compounds /substituents.

Table 2. IR spectral data of Pyrazoline derivatives (1-6).

\begin{tabular}{|c|c|c|c|c|c|c|c|c|c|}
\hline 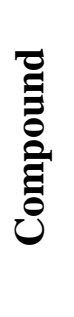 & \begin{tabular}{l}
$\pi^{\prime}$ \\
$\vdots$ \\
\hdashline
\end{tabular} & 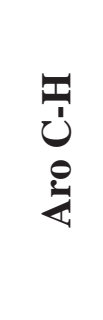 & $\bigcup^{\prime \prime}$ & 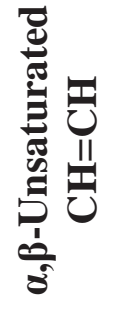 & $\pi^{Z}$ & $\begin{array}{l}0 \\
\text { U1 } \\
\text { بn }\end{array}$ & 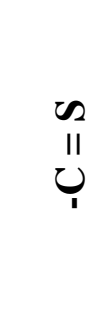 & $\bar{z}_{i}^{N}$ & $\begin{array}{l}0 \\
\text { II } \\
\text { W } \\
\text { II } \\
0\end{array}$ \\
\hline 1 & 2927 & 3060 & 1505 & 1597 & - & 1650 & - & - & - \\
\hline 2 & 2921 & 3024 & 1510 & & 1589 & 1678 & & 3479,3275 & \\
\hline 3 & 2918 & 3037 & 1469 & & 1568 & - & 1266 & 3479,3357 & - \\
\hline 4 & 2921 & 3077 & 1504 & & 1578 & - & - & - & - \\
\hline 5 & 2923 & 3098 & 1491 & & 1592 & 1647 & - & - & - \\
\hline 6 & 2921 & 3056 & 1494 & & 1597 & - & - & - & 1323 \\
\hline
\end{tabular}


The ${ }^{1} \mathrm{H}-\mathrm{NMR}$ spectral data of compound 1-6 are given in Table 3. The H- $\alpha$ and H- $\beta$ protons of chalcones occur as two doublets in the ranges $7.49 \mathrm{ppm}(\mathrm{H}-\alpha)$ and $7.78 \mathrm{ppm}(\mathrm{H}-\beta)$ in the ${ }^{1} \mathrm{H}$ NMR spectra. ${ }^{1} \mathrm{H}-\mathrm{NMR}$ spectra suggest, $7.49 \mathrm{ppm}$ the $\mathrm{C} \alpha-\mathrm{H}$ and $7.78 \mathrm{ppm} \mathrm{CB-H}$ protons are considerably shifted downfield to the extent that they appear in the aromatic region 7.21-7.94. As a result, these protons can hardly be distinguished from those of the aromatic rings. This is probably associated with the joint deshielding resonance and anisotropic effects of the groups bonded to $\beta$-carbon atom, and the disappearance of the aldehydic proton 9-10 ppm is a good evidence for the formation of product.

Table 3. ${ }^{1}$ HNMR spectral data of Pyrazoline derivatives (1-6).

\begin{tabular}{|c|c|c|c|c|c|c|c|c|}
\hline \multirow{2}{*}{} & $-\mathbf{C H}_{\mathbf{3}}$ & $\mathbf{H} \boldsymbol{\alpha}$ & $\mathbf{H \beta}$ & $-\mathbf{C H}_{\mathbf{A}}$ & $-\mathbf{C H}_{\mathbf{B}}$ & $-\mathbf{C H}_{\mathbf{X}}$ & $-\mathbf{N H}_{\mathbf{2}}$ & $\begin{array}{c}\text { Aromatic } \\
\text { protons }\end{array}$ \\
\hline 1 & 2.44 & 7.49 & 7.78 & & & & & $7.21-7.94$ \\
\hline 2 & 2.34 & & & 3.16 & 3.79 & 5.52 & 6.63 & $7.16-7.62$ \\
\hline 3 & 2.39 & & & 3.14 & 3.74 & 5.47 & 7.27 & $6.83-7.59$ \\
\hline 4 & 2.35 & & & 3.10 & 3.80 & 5.21 & & $6.75-7.62$ \\
\hline 5 & 2.37 & & & 3.09 & 3.78 & 5.20 & & $6.76-7.62$ \\
\hline 6 & 2.41 & & & 3.10 & 3.83 & 5.46 & & $7.13-7.72$ \\
\hline
\end{tabular}

The ${ }^{1} \mathrm{H}$ NMR spectra of products showed characteristics ABX system due to geminalvicinal multiple coupling between $4-\mathrm{CH}_{2}$ and 5- $\mathrm{CH}$ protons. The high field double doublet at $\delta$ 3.09-3.16 and $\delta 3.74-3.83$ due to $\mathrm{H}_{\mathrm{A}}$ and $\mathrm{H}_{\mathrm{B}}$ respectively of $\mathrm{C}-4$ protons and low field $\delta$ 5.20-5.52 due to $\mathrm{Hx}$ at $\mathrm{C}-5$ are characteristics signals due to vicinal coupling with the two magnetically nonequivalent protons of methylene group at position 4 of the pyrazolines ring. In all the compounds absorption as multiplet at $\delta 6.75-7.94$ was assigned to aromatic protons ${ }^{13} \mathrm{C}$-NMR spectra of all compounds were recorded in DMSO and $\mathrm{CDCl}_{3}$, spectral signals which are in good agreement with the probable structures. The ${ }^{13} \mathrm{C}-\mathrm{NMR}$ spectral data of compounds 1-6 are given in Table 4.

The most important features of ${ }^{13} \mathrm{C}$-NMR spectra of synthesized chalcone is the $\beta$ carbon atom resonance at $142.04 \mathrm{ppm}$ which appeared down field of $\alpha$-carbon atom at 118.7 ppm because of mesomeric deshielding effect of the carbonyl group [22]. The $\mathrm{C}_{4}$ and $\mathrm{C}_{5}$ carbon of pyrazolines resonated at 43.0-43.7 and 59.5-64.2 ppm, respectively. The carbon of $-\mathrm{CH}_{3}$ in all compounds resonates at 21.4-30.3 ppm, respectively.

The carbon of $(\mathrm{C}=\mathrm{O})$ displayed signals at 155.4-187.7. All the compounds showed signal at 113.3-141.8 ppm were assigned to the aromatic carbon. All the compounds 1-6 showed signals at 151.01-157.2 ppm assigned to $(\mathrm{C}=\mathrm{N})$. 
Table 4. ${ }^{13}$ CNMR spectral data of Pyrazoline derivatives (1-6).

\begin{tabular}{|c|c|c|c|c|c|c|c|c|c|}
\hline Compound & $-\mathrm{CH}_{3}$ & $\mathrm{Ca}$ & $\mathbf{C} \beta$ & $-\mathrm{CH}_{2}$ & $-\mathbf{C H}$ & $-\mathrm{C}=\mathrm{O}$ & $-\mathrm{C}=\mathrm{S}$ & $-\mathrm{C}=\mathrm{N}$ & 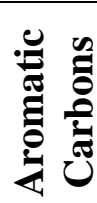 \\
\hline 1 & $\begin{array}{l}\hat{0} \\
\stackrel{0}{0}\end{array}$ & $\stackrel{\hat{\infty}}{\stackrel{\infty}{=}}$ & $\stackrel{\check{I}}{\stackrel{I}{I}}$ & & & $\stackrel{r}{i}$ & & & 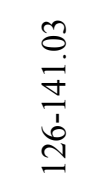 \\
\hline 2 & $\stackrel{n}{\sim}$ & & & $\begin{array}{l}\check{0} \\
\ddot{\gamma}\end{array}$ & $\hat{\hat{n}}$ & $\begin{array}{l}\text { mे } \\
\hat{n} \\
n\end{array}$ & & $\begin{array}{l}\infty \\
\infty \\
\\
\end{array}$ & $\begin{array}{l}\stackrel{3}{+} \\
\dot{+} \\
\dot{j} \\
\dot{d} \\
\stackrel{d}{J}\end{array}$ \\
\hline 3 & $\frac{J}{\dot{\sim}}$ & & & $\begin{array}{l}\stackrel{0}{f} \\
\dot{f}\end{array}$ & $\begin{array}{l}\text { nे } \\
\text { in }\end{array}$ & & $\begin{array}{l}\text { ñ } \\
\stackrel{2}{2}\end{array}$ & $\frac{\widetilde{\alpha}}{\underline{n}}$ & 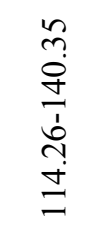 \\
\hline 4 & $\begin{array}{l}\vec{i} \\
\stackrel{i}{i}\end{array}$ & & & 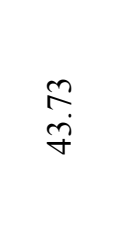 & $\begin{array}{l}\text { ָे } \\
\text { }\end{array}$ & & & $\underset{\vec{n}}{\vec{n}}$ & 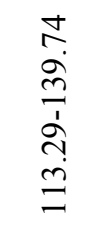 \\
\hline 5 & $\stackrel{\stackrel{B}{+}}{\vec{N}}$ & & & $\begin{array}{l}\vec{\sigma} \\
\dot{p}\end{array}$ & $\stackrel{\hat{i}}{i}$ & 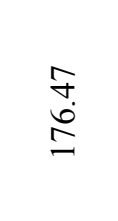 & & $\begin{array}{l}\text { ô. } \\
\dot{b} \\
\stackrel{n}{n}\end{array}$ & 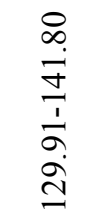 \\
\hline 6 & $\begin{array}{l}\text { m. } \\
\text { in }\end{array}$ & & & 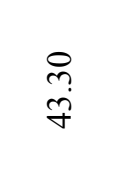 & 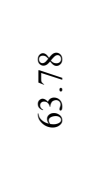 & & & \begin{tabular}{l}
$\stackrel{\text { \} }{2}} \\
{\stackrel{n}{n}}$ & 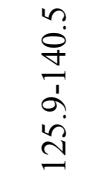 \\
\hline
\end{tabular}
\end{tabular}

The $\mathrm{C}_{4}$ and $\mathrm{C}_{5}$ carbon of pyrazolines resonated at 43.0-43.7 and 59.5-64.2 ppm, respectively. The carbon of $-\mathrm{CH}_{3}$ in all compounds resonates at 21.4-30.3 ppm, respectively. The carbon of $(\mathrm{C}=\mathrm{O})$ displayed signals at 155.4-187.7. All the compounds showed signal at 113.3-141.8 ppm were assigned to the aromatic carbon. All the compounds 1-6 showed signals at 151.01-157.2 ppm assigned to $(\mathrm{C}=\mathrm{N})$. The $\mathrm{C}_{4}$ and $\mathrm{C}_{5}$ carbon of pyrazolines resonated at 43.0-43.7 and 59.5-64.2 ppm, respectively. The carbon of $-\mathrm{CH}_{3}$ in all compounds resonates at 21.4-30.3 ppm, respectively. The carbon of $(\mathrm{C}=\mathrm{O})$ displayed signals at 155.4187.7. All the compounds showed signal at 113.3-141.8 ppm were assigned to the aromatic carbon. All the compounds 1-6 showed signals at 151.01-157.2 ppm assigned to $(C=N)$. 


\section{1. Antidibetic acticity}

Pancreas is the primary organ involved in sensing the organism's dietary and energetic states via glucose concentration in the blood and in response to elevated blood glucose, insulin is secreted. Alloxan is one of the usual substances used for the induction of diabetes mellitus apart from streptozotocin. Alloxan has a destructive effect on the beta cells of the pancreas [23-24]. Alloxan causes a massive reduction in insulin release by the destruction of b-cells of the islets of langerhans, thereby inducing hyperglycaemia [25] Insulin deficiency leads to various metabolic alterations in the animals viz increased blood glucose, increased cholesterol, increased levels of alkaline phosphate and transaminases [26-27].

All the compounds were screened in vivo for their oral hypoglycemic activity by alloxaninduced diabetic model in rat. The antidiabetic screening effect of pyrazoline derivatives is shown in Table 5 and the Clustered column Chart 1. All the compounds are having remarkable hypoglycemic property, however with a degree of variation.

A significant increase in blood glucose was observed in diabetic rats. All the compounds 1-6 had shown significant reduction in blood glucose as compared to control diabetic rats at $150 \mathrm{mg} / \mathrm{kg}$ body weight for 4 th and 5 th hours. Insulin was taken as standard drug which showed $28.53 \%$ blood glucose lowering activity at the dose of $100 \mathrm{mg} / \mathrm{kg}$. p.o. Among all the derivatives, compound $4(22.09 \%)$ was found to be better hypoglycemic agent compare with standard drug insulin $(19.96 \%)$ in reducing the blood glucose level. It is interesting to note that Compounds $1(19.64 \%)$ and $3(16.03 \%)$ showed an appreciable increase in hypoglycemic activity at $50 \mathrm{mg} / \mathrm{kg}$. Compound $6(13.23 \%)$ comparatively had shown moderate hypoglycemic activity. Compound $2(12.53 \%)$ and 5 (12.25 \%) comparatively had shown poor hypoglycemic activity .

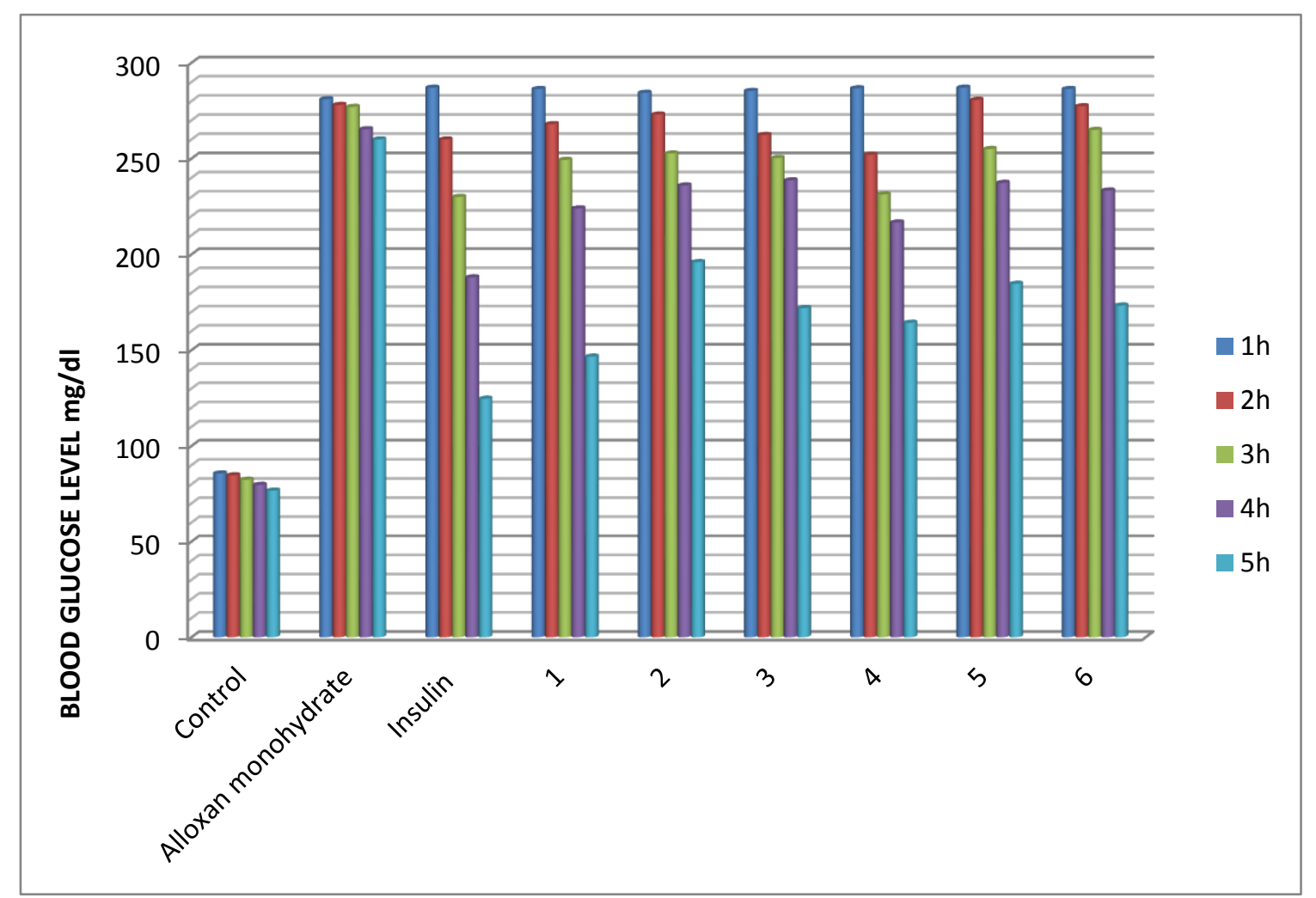

Chart 1. Antidiabetic activity of pyrazoline derivatives 1-6. 
Table 5. Anti-Diabetic activity of synthesized test compounds of pyrazoline derivatives (1-6).

\begin{tabular}{|c|c|c|c|c|c|c|c|}
\hline \multirow{2}{*}{ S. No. } & \multirow{2}{*}{ Groups } & \multicolumn{5}{|c|}{ Blood Glucose Levels (mg/dl) } & \multirow{2}{*}{$\begin{array}{c}\% \text { Anti } \\
\text { hyperglyce } \\
\text { mic } \\
\text { activity }\end{array}$} \\
\hline & & $1 \mathrm{~h}$ & $2 \mathrm{~h}$ & $3 \mathrm{~h}$ & $4 \mathrm{~h}$ & $5 \mathrm{~h}$ & \\
\hline 1 & Control & $\begin{array}{l}85.66 \\
\pm 1.53\end{array}$ & $\begin{array}{l}84.67 \\
\pm 0.58\end{array}$ & $\begin{array}{l}82.33 \\
\pm 0.59\end{array}$ & $\begin{array}{r}79.67 \\
\pm 1.52\end{array}$ & $\begin{array}{r}76.67 \\
\pm 5.77\end{array}$ & \\
\hline 2 & $\begin{array}{c}\text { Alloxan } \\
\text { monohydr } \\
\text { ate }\end{array}$ & $\begin{array}{c}281.00 \\
\pm 2.64\end{array}$ & $\begin{array}{c}278.00 \\
\pm 2.00\end{array}$ & $\begin{array}{c}277.00 \\
\pm 1.00\end{array}$ & $\begin{array}{l}265.33 \\
\pm 3.05\end{array}$ & $\begin{array}{c}260.00 \\
\pm 1.00\end{array}$ & \\
\hline 3 & Insulin & $\begin{array}{c}287.00 \\
\pm 2.00\end{array}$ & $\begin{array}{c}260.00 \\
\pm 2.16\end{array}$ & $\begin{array}{c}230.00 \\
\pm 8.00\end{array}$ & $\begin{array}{c}188.00 \\
\pm 1.00\end{array}$ & $\begin{array}{c}124.67 \\
\pm 1.17\end{array}$ & 28.53 \\
\hline 4 & 1 & $\begin{array}{c}286.33 \\
\pm 2.52\end{array}$ & $\begin{array}{c}268.00 \\
\pm 2.78\end{array}$ & $\begin{array}{c}249.33 \\
\pm 1.15\end{array}$ & $\begin{array}{c}224.00 \\
\pm 4.00\end{array}$ & $\begin{array}{c}146.67 \\
\pm 4.16\end{array}$ & 19.64 \\
\hline 5 & 2 & $\begin{array}{c}284.33 \\
\pm 4.16\end{array}$ & $\begin{array}{c}273.00 \\
\pm 4.36\end{array}$ & $\begin{array}{c}252.67 \\
\pm 3.05\end{array}$ & $\begin{array}{c}236.00 \\
\pm 4.13\end{array}$ & $\begin{array}{c}196.00 \\
\pm 5.29\end{array}$ & 12.53 \\
\hline 6 & 3 & $\begin{array}{c}285.33 \\
\pm 4.18\end{array}$ & $\begin{array}{c}262.33 \\
\pm 5.85\end{array}$ & $\begin{array}{c}250.33 \\
\pm 3.21\end{array}$ & $\begin{array}{c}238.67 \\
\pm 3.05\end{array}$ & $\begin{array}{c}172.00 \\
\pm 5.28\end{array}$ & 16.03 \\
\hline 7 & 4 & $\begin{array}{c}286.67 \\
\pm 5.03\end{array}$ & $\begin{array}{c}252.00 \\
\pm 4.00\end{array}$ & $\begin{array}{c}231.33 \\
\pm 4.16\end{array}$ & $\begin{array}{c}216.67 \\
\pm 3.55\end{array}$ & $\begin{array}{c}164.33 \\
\pm 4.04\end{array}$ & 22.09 \\
\hline 8 & 5 & $\begin{array}{c}287.00 \\
\pm 5.56\end{array}$ & $\begin{array}{c}280.67 \\
\pm 3.05\end{array}$ & $\begin{array}{c}255.00 \\
\pm 3.00\end{array}$ & $\begin{array}{c}237.33 \\
\pm 3.51\end{array}$ & $\begin{array}{c}184.67 \\
\pm 2.49\end{array}$ & 12.25 \\
\hline 9 & 6 & $\begin{array}{c}286.33 \\
\pm 6.65\end{array}$ & $\begin{array}{c}277.33 \\
\pm 3.06\end{array}$ & $\begin{array}{c}265.00 \\
\pm 3.00\end{array}$ & $\begin{array}{c}233.33 \\
\pm 4.16\end{array}$ & $\begin{array}{c}173.33 \\
\pm 2.47\end{array}$ & 13.23 \\
\hline
\end{tabular}

Data presented above are mean \pm standard deviation $(\mathrm{M} \pm \mathrm{SD})$ values of three replicate. 
Alloxan causes diabetes by the rapid depletion of $\beta$-cells and thereby brings about a reduction of insulin release. In our study, an increase in blood glucose level in diabetic rats confirmed the induction of diabetes mellitus [28]. The oral administration of a single dose of synthesized compounds caused a significant reduction in blood glucose in diabetic rats. These results revealed that pyrazoline derivatives may be effective in insulin-independent diabetes mellitus. The significant hypoglycemic effects of pyrazoline derivatives in diabetic rats indicate that it can be mediated by stimulation of glucose utilization by peripheral tissues.

From the observed result it is concluded that almost all the compounds 1-6 reduced glucose level in diabetic rats. However, the effect of compound $\mathbf{4}$ is more pronounced in alloxan diabetic rat

\section{CONCLUSION}

In this present work an attempt has been made to synthesize some new pyrazoline derivatives and to study their anti-dibetic activity. (E)-1,3-dip-tolylprop-2-en-1-one (1) was prepared by reaction of 4-methylacetophenone with 4-methylbenzaldehyde in dilute methanolic sodium hydroxide solution under ultrasonic irradiationin the water bath of an ultrasonic cleaner at room temperature.

The chalcone was then reacted with semicarbazidehydrochloride, thiosemicarbazide, phenylhydrazine hydrochloride, benzhydrazide and benzene sulphonylhydrazide to give 4,5dihydro-3,5-dip-tolylpyrazole-1-carboxamide(2),4,5-dihydro-3,5-dip-tolylpyrazole-1carbothioamide (3),4,5-dihydro-1-phenyl-3,5-dip-tolyl-1H-pyrazole(4),(4,5-dihydro-3,5-diptolylpyrazol-1-yl)(phenyl)methanone(5),3,5-bis(4-methylphenyl)-1-(phenylsulfonyl)-4,5-

dihydro-1H-pyrazole(6). It is noteworthy to mention that, among all the derivatives, compounds 1,3,4 and $\mathbf{6}$ were found to be better hypoglycemic agent compare with standard drug insulin in reducing the blood glucose level.

\section{References}

[1] Maiti R., Jana D., Das U. K., Ghosh D., J. Ethnopharmacol 92 (2004) 85-91.

[2] World Health Organization; Fact sheet No-312, November 2009. http://www.who.int/mediacentre/factsheets/fs312/en/index.html

[3] Susheela T., Padma Balaravi, Jane Theophilus, Narender Reddy, Reddy P. U. M., Curr. Sci. 94(9) (2008) 1191.

[4] Diabetes Statistics: India Is the Diabetic Capital of The World, $\mathrm{http} / /$ health.savvy-cafe.com/diabetes-statistics-india-is-the-diabetic-capital-of-the-world.

[5] Bhupesh C. M., Kamal S., Nagendra S. C., Rohit B., Kalyani D., Int. J. Pharm. 6 (2008) $1-6$.

[6] Gerritsen G. C., Dulin W. E., Kalamazoo P. D., Diabetes 14 (1965) 102.

Smith D. L., Forist A. A., Dulin W. E., J. Med. Chem. 1965, 350.

[7] ElShora AI., Egypt J. Sol. 23 (2000) 251-254

[8] Sobhia H. R., Yaminib Y., Esrafili A., Adiba M., J. Pharm, Biomed. Anal. 45 (2008) 316-320. 
[9] Nauduri D., Reddy G. B., Pharm. Bull. Tokyo 46 (1998) 1254.

[10] Korgaokar S. S., Patil P. H., Shah M. T., Parekh H. H., Indian J. Pharm. Sci. 58 (1996) 222.

[11] Udupi R. H., Kushnoor A. R., Bhat A. R., Indian J. Heterocyclic Chem. 8 (1998) 63.

[12] Delay F. (S. A. Fermeinch), Patentschriff (Switz) C. A. 117 (1992) 90276f.

[13] Geigy J. R., Belg, 466668, Aug. 31, 1942; C.A., 39 (1945) 7848.

[14] Reddy D. B., Senshama T., Ramma Reddy B. M. V., Indian J. Chem. 30(B) (1991) 46.

[15] Zalgislaw K.. Zbigniew, Acta. Pol Pharm 36(6) (1979) 645: C.A., 93 (1980) 204525e.

[16] Yamashita Hiroyuti, Odata Mocoto, Kawazara Hirahi, Namekawa Hiroshi, Eur. Patent appl. Ep1988; 295695CL.Co7D401/6) J. P. Appl.87(1987)148919, C.A, 111(1989)2351

[17] Bauer A. N., Kirby W. N. M., Sherries J. C., Truck M., Am. J. Clin. Pathol. 45 (1996) 493 (1996).

[18] Yanarday R., Colak H., Pharm Pharmacol Comno 4 (1998) 309.

[19] Ragini Gupta, Neetu Gupta, Anshu Jain, Indian Journal of Chemistry 49B (2010) 351-355

[20] Naglaa M. A. E., Tamer S. S., Mohamed F. M., Ultrason. Sonochem. 16 (2009) 70.

[21] C. Guofeng, L. Jitai, D. Huiyun, L. Tongshuang, C. J. I. 6 (1), 6 (2004).

[22] D. Azarifar, M. Shaebanzadeh, Molecules 7 (2002) 885.

[23] Prince S. M., Menon V. P., J. Ethnopharmacol. 70 (2000) 9-15.

[24] Jelodar G., Mohsen M., Shahram S., African J. Traditional, Complementary and Alternative Medicines 3 (2003) 299-305.

[25] Grover J. K., Vats V., Rathi S. S., J. Ethnopharmacol. 73 (2000) 461-470.

[26] Shanmugasundaram K. R., Panneerselvam S. P., Shanmugasundaram E. R. B., R. Br. J. Ethnopharmacol. 7 (1983) 205-216..

[27] Begum N., Shanmugasudnaram K. R., J. Health Sci. 4 (1978) 129-139.

[28] Mohamed A. K., Bierhaus A., Sciekofer S., Tritschler H., Ziegler H., Nawroth P. P., Biofactors 10 (1999) 175. 